\title{
IMPROVEMENT OF HAMSTER-LUNG FIBROSIS MODEL BY REPEATED INTRATRACHEAL ADMINISTRATION OF BLEOMYCIN
}

\author{
Shinichiro Ikezaki, Akiyoshi Nishikawa, Fumio Furukawa, Tomonori Enami, \\ Zen-yo Tanakamaru, Hyoung-Chin Kim, \\ and Michihito Takahashi \\ Division of Pathology, National Institute of Health Sciences
}

Shoji Fukushima

lst Department of Pathology, Osaka City University, School of Medicine

\begin{abstract}
Suitable conditions of bleomycin (BLM)-treatment to effectively induce pulmonary fibrosis without high mortality were investigated in Syrian golden hamsters. Male 6-week-old hamsters were divided into 5 groups, each consisting of 5 animals. Groups 1-4 were intratracheally instilled with $2.5 \mathrm{U} / \mathrm{kg}$ of BLM on day 0 and then repeatedly given BLM as follows: group $1,2.5 \mathrm{U} / \mathrm{kg}$ intratracheally on day 14 ; group $2,1.0 \mathrm{U} / \mathrm{kg}$ intratracheally on day 14 ; group $3,1.0 \mathrm{U} / \mathrm{kg}$ intratracheally each on days 7 and 14 ; group 4, $20 \mathrm{U} / \mathrm{kg}$ intraperitoneally each on days 10 and 14 . Group 5 served as a vehicle control. The survival rate was 4/5 (80\%) in groups 1 and 3, and 5/5 (100\%) in other groups. One animal each in groups 1 and 3 was found dead on day 22, of which lungs histopathologically showed evident fibrosis accompanied with congestion, edema, inflammatory cell infiltration, and hemorrhage. The lung weight at the termination of the experiment on day 28 was the highest in group 1 , and significantly higher in groups $1(\mathrm{p}<0.01)$ and $2(\mathrm{p}<0.05)$ than in group 5 , well correlating with the histopathological severity of lung fibrosis. The lung weight of group 3 was also higher as compared to the group 5 value although this was not statistically significant and the lung weight of group 4 was almost comparable to that of group 5, again being in line with the histopathology of the lung. The results in the present study thus suggest that the repeated intratracheal instillation with $2.5 \mathrm{U} / \mathrm{kg}$ BLM at intervals of 2 weeks may offer a favorable condition to induce diffuse lung fibrosis in hamsters. (J Toxicol Pathol $9: 23 \sim 28,1996$ )

Key words : Hamster, Lung fibrosis, Bleomycin
\end{abstract}

\section{Introduction}

Animal models for human diffuse interstitial pneumonia have been introduced in rodents including hamsters by treatment with pneumotoxic agents such as bleomycin (BLM) ${ }^{1,2}$. Although BLM has been clinically used for the therapy of some malignant tumors such as malignant lymphomas and testicular carcinomas ${ }^{3,4}$, it has been shown to cause fatal pulmonary fibrosis as a serious adverse effect ${ }^{3,5}$. Since then a number of experiments using BLM have been widely performed with rodents to elucidate the path-

池崎信一郎 西川秋佳 古川文夫 榎並倫宣 田中丸善洋 金 烹津 高橋道人 福島昭治

Accepted for publication: September 24, 1995

Mailing address : Akiyoshi Nishikawa, Division of Pathology, National Institute of Health Sciences, 1-18-1 Kamiyoga, Setagaya-ku, Tokyo 158, Japan. ogenesis of idiopathic interstitial pneumonia ${ }^{6,7}$, and further to assess potentially desirable antifibrotic agents $^{8-10}$. Although both the systemic (intraperitoneal) administration and the local (intratracheal) instillation have been applied for BLM treatment inducing lung fibrosis in rodents, the latter method is now considered to be more effective ${ }^{1,12}$. In the existing lung fibrosis models, BLM has been usually administered as a single dose ${ }^{13,14}$. Therefore, relatively large doses of BLM have been used and thus the mortality has been high ${ }^{13}$. Meanwhile, it has been shown that the Syrian golden hamster is particularly suitable for examining the effects of carcinogenic substances which may target the respiratory tract ${ }^{15}$.

Because of such disadvantages in the previous models, several conditions including doses, routes, frequency, and intervals of BLM treatments remain to be improved. In the present study, we investigated 
suitable experimental conditions with hamsters in order to effectively induce diffuse lung fibrosis and to make the survival long.

\section{Materials and Methods}

\section{Animals and chemical}

Male 6-week-old Syrian golden hamsters (Japan SLC, Inc., Shizuoka) were used in this experiment. They were housed in plastic cages, five hamsters/cage, under standard laboratory conditions (room temperature, $23 \pm 2^{\circ} \mathrm{C}$; relative humidity, $55 \pm$ $5 \%$; a $12 \mathrm{~h} / 12 \mathrm{~h}$ light/dark cycle), and were given basal diet (Oriental MF, Oriental Yeast Co., Tokyo, Japan) and tap water ad libitum. Bleomycin hydrochloride (BLM) was the generous donation of Nippon Kayaku Co., Ltd. (Tokyo, Japan).

\section{Experimental protocols}

Twenty five hamsters were randomly divided into five groups, each consisting of 5 animals, as shown in Fig. 1. Animals in groups 1-4 were instilled intratracheally under pentobarbital anesthesia $(40 \mathrm{mg} / \mathrm{kg})$ with BLM solution dissolved in physiological saline at $2.5 \mathrm{U} / 5 \mathrm{ml} / \mathrm{kg}$ body weight on day 0 . Hamsters in groups 1-3 were further instilled with BLM by a tracheal route. Groups 1 and 2 were respectively given 2.5 and $1.0 \mathrm{U} / \mathrm{kg}$ BLM on day 14 and group 3 was twice given $1.0 \mathrm{U} / \mathrm{kg}$ BLM on days 7 and 14. In group 4, animals were twice injected intraperitoneally with $20 \mathrm{U} / \mathrm{kg}$ BLM on days 10 and 14. The doses of BLM were determined according to the data in the previous experiments ${ }^{13}$. Group 5 served as a vehicle control of BLM treatment which was instilled intratracheally with an equivalent volume of physiological saline on days 0,7 and 14 . On day 28, all surviving animals were sacrificed under ether anesthesia by exsanguination. Dead animals were also completely autopsied. At autopsy, the resected lungs were weighed and routinely processed for histopathological examination. Briefly, after prefixation via the trachea with UFIX (SAKURA FINTECHNICAL CO ; LTD), the lung lobes were fixed with substantial amounts of UFIX, embedded in paraffin, and sections were stained with hematoxylin and eosin. The severity of lung fibrosis was histologically interpreted as follows: - , absence; \pm , questionable area; + , a few foci ; $H$, scattered foci; $\#$, diffuse. The statistical significance of inter-group differences was evaluated using the Student's $t$-test.

\section{Results}

Survival rate, body weight gain, and lung weights

Each one animal in groups 1 and 3 died on day

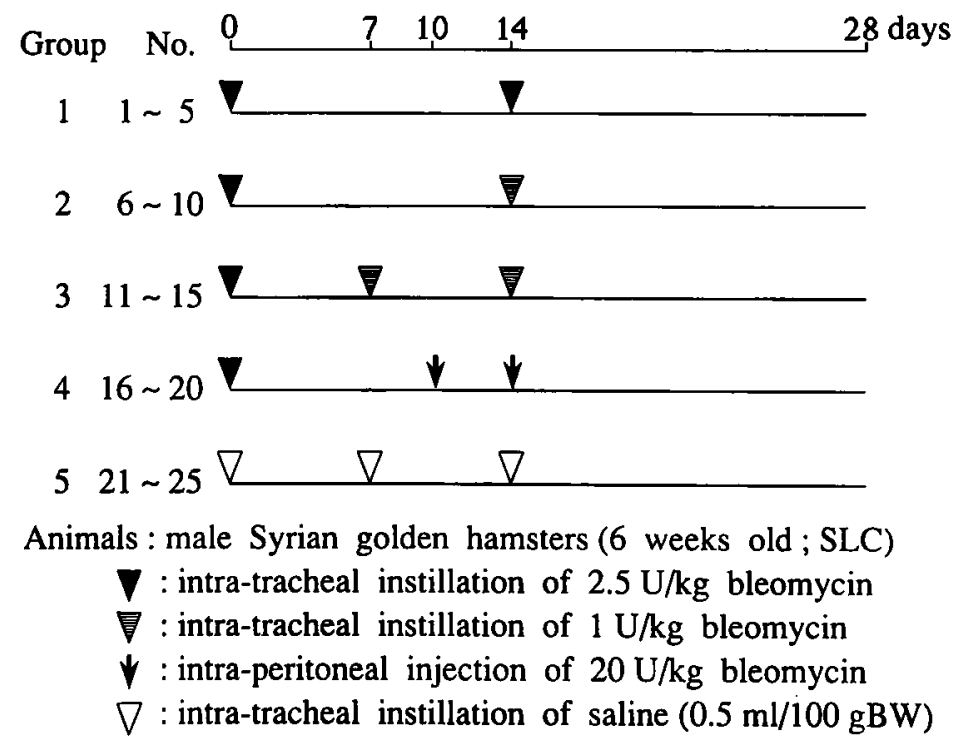

Fig. 1. Experimental design. 
Table 1. Survival Rate, Body Weight Gain, and Degree of Pulmonary Fibrosis in Hamster Lungs Treated with Bleomycin

\begin{tabular}{cccccccccc}
\hline \multirow{2}{*}{ Group } & $\begin{array}{c}\text { Initial no. } \\
\text { of } \\
\text { animals }\end{array}$ & $\begin{array}{c}\text { Survival } \\
\text { rate }\end{array}$ & $\begin{array}{c}\text { Body weight } \\
\text { gain }(\mathrm{g})\end{array}$ & \multicolumn{5}{c}{ Fibrosis } \\
\cline { 7 - 10 } & 5 & $4 / 5$ & $12.7 \pm 17.12$ & & & & 3 & 1 \\
2 & 5 & $5 / 5$ & $36.6 \pm 8.85$ & 1 & 1 & 3 & & \\
3 & 5 & $4 / 5$ & $29.5 \pm 8.78$ & & 1 & 1 & 2 & \\
4 & 5 & $5 / 5$ & $31.8 \pm 8.88$ & 2 & 3 & & & \\
5 & 5 & $5 / 5$ & $35.9 \pm 14.08$ & 5 & & & & \\
\hline
\end{tabular}

a) - ; indicating the absence of fibrosis \pm ; the presence of areas with questionable fibrosis + ; a few foci of fibrosis \# ; scattered foci of fibrosis \# ; diffuse fibrosis

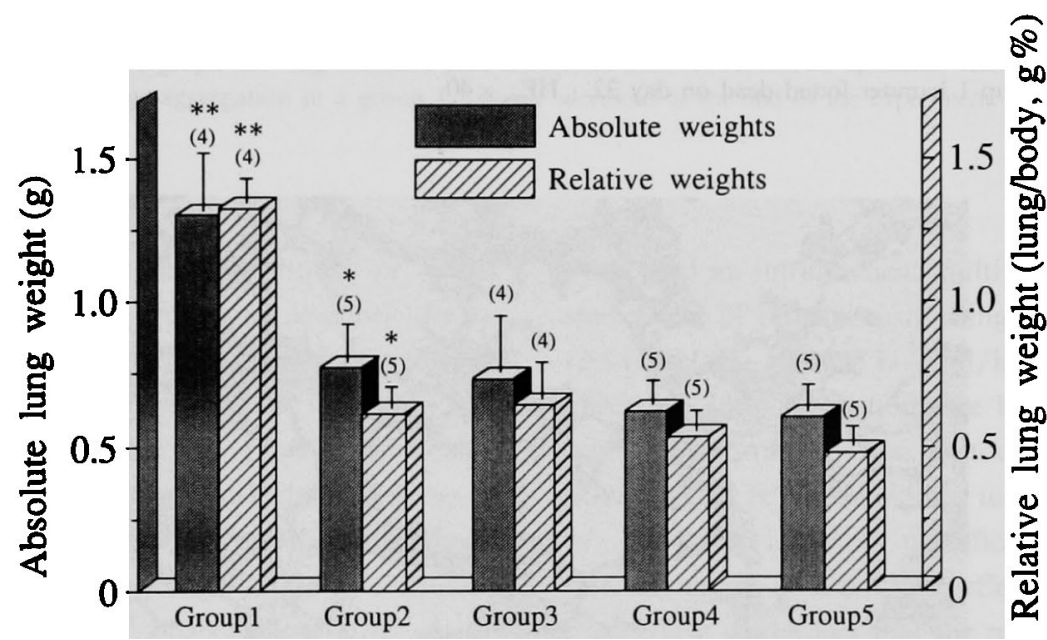

*,** : Significantly different from Group $5 .(*: p<0.05, * *: p<0.01)$

( ) : No. of animals.

Fig. 2. Absolute and relative lung weights of hamsters.

22 and thus the survival rate was $4 / 5(80 \%)$ in these groups and 5/5 (100\%) in the other groups (Table 1). In addition to the improvement on mortality, the deaths in groups 1 and 3 occurred at a latter stage (on day 22) of the present experimental period as compared to our previous experiment in which dead animals appeared in 7 days $^{13}$. Body weight gain calculated from the mean initial body weight $(89.5-92.7 \mathrm{~g})$ was respectively $12.7,36.6,29.5,31.8$, and $35.9 \mathrm{~g}$ in groups 1-5 (Table 1). Although group 1 showed a lower body weight gain than the control group (group 5), there was no statistical significance. Absolute and relative lung weights in each group at the termination of the experiment are illustrated in Fig. 2. The mean wet absolute weight was respectively $1.298,0.772$, $0.734,0.619$, and $0.602 \mathrm{~g}$ in groups $1-5$. The mean relative weight was respectively $1.330,0.627,0.652$, 0.542 , and $0.498 \mathrm{~g} \%$ in groups $1-5$. Thus both absolute and relative lung weights were significantly increased in groups $1(\mathrm{p}<0.01)$ and $2(\mathrm{p}<0.05)$ as compared to the saline-treated control value.

\section{Histopathology of the lungs}

In the lungs of dead hamsters, histopathologically, evident fibrosis was observed in association with marked congestion, perivascular and intraalveolar edema, inflammatory cell infiltration and hemorrhage (Fig. 3).

Although interstitial fibrosis was noted in the lungs of all BLM-treated groups sacrificed at the end of the experiment (Fig.4), the severity was greatly different among groups. Lung fibrosis in group 1 


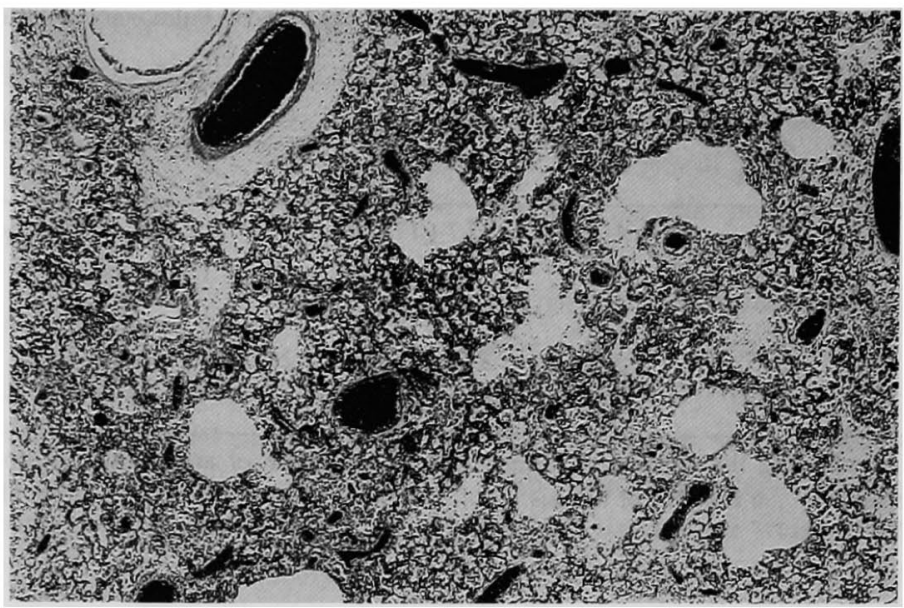

Fig. 3. A microphotograph showing fibrosis, perivascular edema, inflammatory cell infiltration and hemorrhage in a group 1 hamster found dead on day 22. HE, $\times 40$

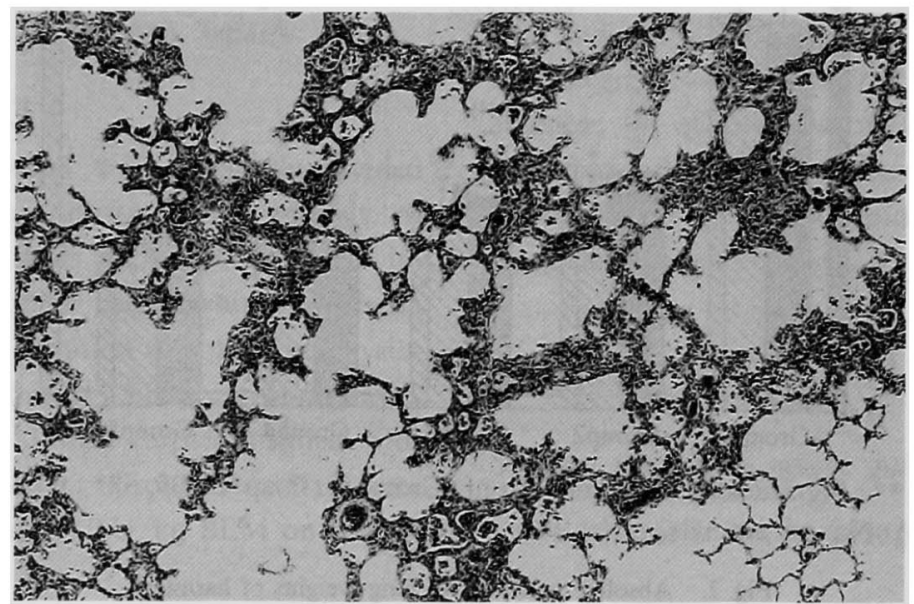

Fig. 4. A microphotograph showing interstitial fibrosis in a group 1 hamster sacrificed at the end of the experiment. HE, $\times 80$

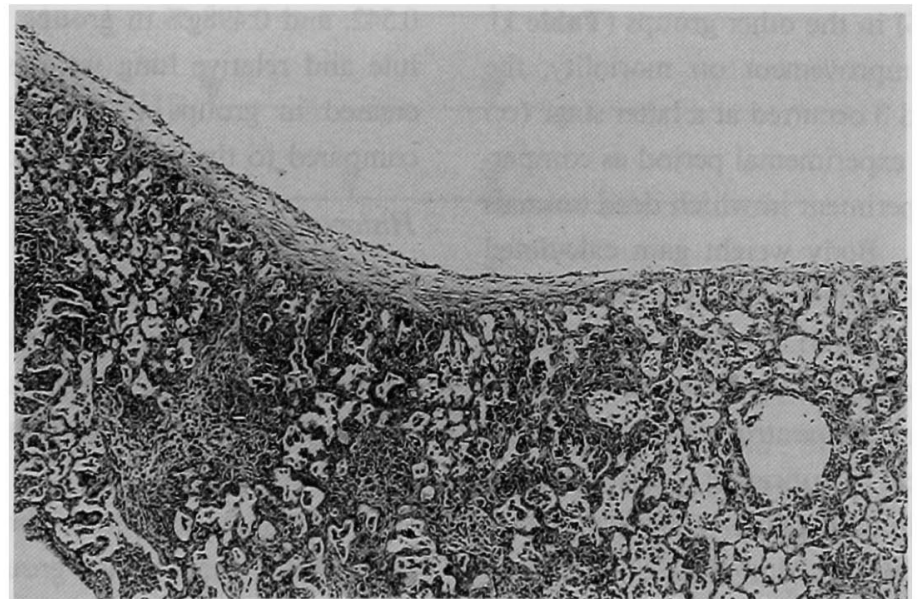

Fig. 5. A microphotograph showing remarkable pulmonary fibrosis and thickening of the visceral pleura in a group 1 hamster sacrificed at the end of the experiment. $\mathrm{HE}, \times 80$ 


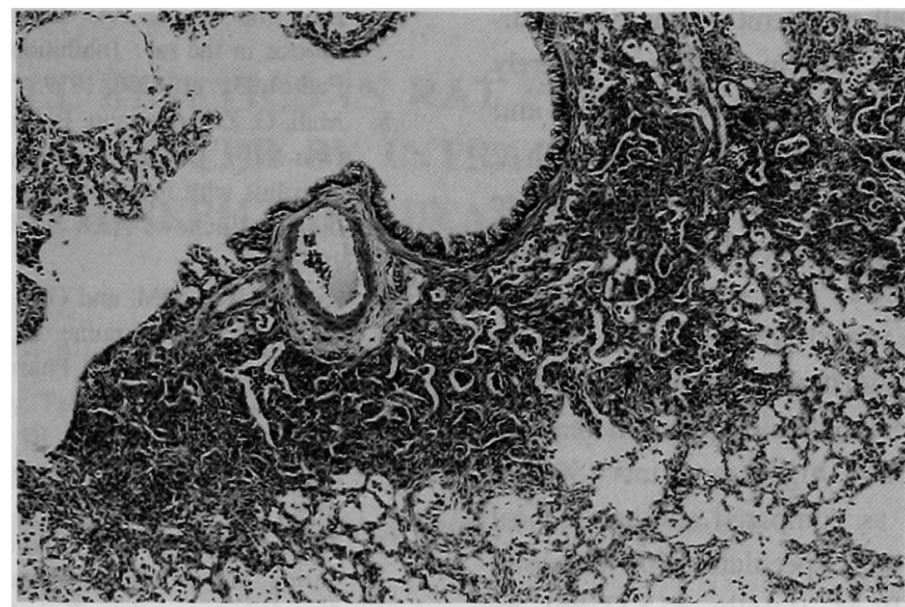

Fig. 6. A microphotograph showing intensive proliferation of bronchioloalveolar epithelial cells in association with macrophage aggregation in a group 1 hamster sacrificed at the end of the experiment. $\mathrm{HE}, \times 80$

was the severest and widely distributed in whole lobes, and that in group 3 the second severest. In the other BLM-treated groups, the degree of lung fibrosis was extremely mild and some animals in groups 2,4 , and 5 lacked fibrosis (Table 1). Fibrotic thickening of the visceral pleura was also marked in the lungs of hamsters treated with BLM, especially of group 1 (Fig. 5). Furthermore the lungs of group 1 showed intensive proliferation of bronchioloalveolar epithelial cells in association with thickened intraalveolar septa and macrophage aggregation in alveolar spaces (Fig. 6), whereas these changes were slighter or absent in groups $2-5$.

\section{Discussion}

In several conditions of BLM-treatments, the group 1 treatment was the most effective to induce diffuse lung fibrosis with low mortality rate (20\%), in which $2.5 \mathrm{U} / \mathrm{kg}$ of BLM was twice given 2 weeks apart intratracheally. The transtracheal approach for BLM administration has been frequently used because of the effectiveness to easily induce lung fibrosis ${ }^{9,16}$, however, this approach has been invariably associated with morbidity and high mortality. Moreover, a single high dose of BLM is usually lethal and makes animals difficult to survive long, ${ }^{9,1213}$. Previously, in fact, we have shown that a single intratracheal instillation of $10 \mathrm{U} / \mathrm{kg}$ BLM caused high mortality $(85 \%)^{13}$.

In order to lower the mortality, Zia et $a h^{17}$ have developed an intratracheal multiple-dose BLM-hamster model of lung fibrosis using 3 consecutive doses ( $2.5 \mathrm{U}, 2.0 \mathrm{U}$, and $1.5 \mathrm{U} / 5 \mathrm{ml} / \mathrm{kg}$ ) per week, which effectively induced a moderate level of lung fibrosis with low mortality. The protocol of group 3 in the present study is almost similar to the model by Zia et $a l$., however, in terms of efficacy to induce lung fibrosis, group 1 was more effective than group 3, irrespective of the fact that the mortality rate was the same in group 1 and 3. Brown et al. ${ }^{18}$ have also proposed a rat lung fibrosis model in which 3 or more doses of BLM are instilled at a dose of $0.5 \mathrm{U} / \mathrm{animal}$ with intervals of a week although the hamster has been suggested to be more favorable than the rat in examining the respiratory tract lesions ${ }^{15}$. Taken together with these data, our results indicate that the repeated intratracheal administration of BLM more efficiently induces lung fibrosis and lowers the mortality, as compared to the single dose approach. It is therefore suggested that more frequent exposure of lower doses of BLM may improve the inducibility of lung fibrosis and reduce the mortality.

The interval of 2 weeks on BLM instillation in groups 1 and 2 may be in good agreement with previous experiments in rodents ${ }^{11,19}$. Namely, in an experiment using single intratracheal administration of BLM in hamsters, it was shown that total numbers of exfoliative cells in bronchiolar lavage fluids were recovered at 10 days after BLM-treatment ${ }^{19}$. Another experiment in rats also demonstrated that 
terminal bronchiolar cell proliferation rapidly occurred after BLM administration in lung areas severely damaged and intraalveolar fibrosis was formed, and thereafter the proliferative activity ceased within 2 weeks ${ }^{11}$. It is suggested from these data that acute alveolar damage may be recovered within 2 weeks after instillation of BLM. That may be the reason why the mortality was improved in group 1 .

Regarding the administrative routes of BLM, it has been shown that the systemic approach requires more frequent dosing and higher amounts $(50 \mathrm{mg} /$ $\mathrm{kg}$; about $95 \mathrm{U} / \mathrm{kg})^{20}$ as compared to the tracheal approach. Therefore, it is speculated that the combined treatments of BLM (totally $42.5 \mathrm{U} / \mathrm{kg}$ ) by intratracheal and intraperitoneal routes in group 4 failed to efficiently induce diffuse lung fibrosis possibly because of still insufficient dosing of BLM.

In conclusion, the hamster lung fibrosis model with repeated intratracheal instillation of $2.5 \mathrm{U} / \mathrm{kg}$ BLM 2 weeks apart may offer a favorable condition, in induction of diffuse lung fibrosis without high mortality.

Acknowledgment : This work was supported by a SRF Grant for Biomedical Research.

\section{References}

1. Crooke, ST, and Bradner, WT : Bleomycin : a review. J Med 7 : 333-428, 1976.

2. Snider, GL, Celli, BR, Goldstein, RH, O'Brien, JJ, and Lucey, EC: Chronic interstitial pulmonary fibrosis produced in hamsters by endotracheal bleomycin : Lung volumes, volume-pressure relations, carbon monoxide uptake, and arterial blood gas studies. Am Rev Respir Dis 117 : 289-297, 1978.

3. Blum, RH, Carter, SK, and Agre, $\mathrm{K}$ : A clinical review of bleomycin : a new antineoplastic agent. Cancer 31 : 903-914, 1972.

4. Burger, RM, Peisach, J, and Horwitz, SB : Mechansisms of bleomycin action: in vitro studies. Life Sci 28 : 715-722, 1981.

5. Fukuda, Y, Ishizaki, M, Masuda, Y, Kimura, G, Kawanami, $O$, and Masugi, $Y$ : The role of intraalveolar fibrosis in the process of pulmonary structural remodeling in patients with diffuse alveolar damage. Am J Pathol 126 : 171-182, 1987.

6. Adamson, IYR, and Bowden, DH : The pathogenesis of bleomycin-induced pulmonary fibrosis in mice. Am J Pathol 77: 185-198, 1974.

7. Thrall, RS, McCormick, JR, Jack, RM, McReynolds,
RA, and Ward, PA: Bleomycin-induced pulmonary fibrosis in the rat : Inhibition by indomethacin. Am J Pathol 95 : 117-130, 1979.

8. Mall, G, Zimmermann, P, Siemens, I, Burkhardt, A, and Otto, HF : Prevention of bleomycin-induced fibrosing alveolitis with indomethacin : sterelogical studies on rat lungs. Virchows Arch A Pathol Anat 419: 339-347, 1991.

9. Zia, S, Hyde, DM, and Giri, SN : Effects of an interferon inducer bropirimine on bleomycin-induced lung fibrosis in hamsters. Pharmcol Toxicol 71:11-18, 1992.

10. Phan, SH, and Fantone, JC : Inhibition of bleomycininduced pulmonary fibrosis by lipopolysaccharide. Lab Invest 50 : 587-591, 1984.

11. Kawamoto, M, and Fukuda, $\mathrm{Y}$ : Cell proliferation during the process of bleomycin-induced pulmonary fibrosis in rats. Acta Pathol Jpn 40 : 227-238, 1990.

12. Snider, GL, Hayes, JA, and Korthy, AL: Chronic interstitial pulmonary fibrosis produced in hamsters by endotracheal bleomycin: Pathology and stereology. Am Rev Respir Dis 117 : 1099-1108, 1978.

13. Enami, T, Nishikawa, A, Furukawa, F, Mitsui, M. Yoshimura, H, Takahashi, M, and Fukushima, S: Protective effects of butylated hydroxyanisole against bleomycin-induced diffuse alveolar damage in hamsters. J Toxicol Pathol 8 : 7-14, 1995.

14. O'Neill, CA, and Giri, SN : Effects of niacin on bleomycin-induced increases in myeloperoxidase, prolyl hydroxylase, and superoxide dismutase activities and collagen accumulation in the lungs of hamsters. $J$ Biochem Toxicol 7 : 229-239, 1992.

15. Montesano, R, Saffiotti, U, and Shubik, $P$ : The role of topical and systemic factors in experimental respiratory carcinogenesis. In : Inhalation Carcinogenesis. Vol. 18, AEC Symposium Series, MG, Hanna, Jr, P, Nettesheim, and JR, Gilbert Ed, 353-371. Oak Ridge, Tennessee. 1970.

16. O'Neill, CA, and Giri, SN : Biochemical mechanisms for the attenuation of bleomycin-induced lung fibrosis by treatment with niacin in hamsters : The role of NAD and ATP. Exp Lung Res 20 : 41-56, 1994.

17. Zia, S, Hyde, DM, and Giri, SN : Development of a bleomycin hamster model of subchronic lung fibrosis. Pathology 24 : 155-163, 1992.

18. Brown, RFR, Drawbaugh, RB, and Marrs, TC: An investigation of possible models for the production of progressive pulmonary fibrosis in the rat. The effects of repeated intratracheal instillation of bleomycin. Toxicol 51 : 101-110, 1988.

19. Osanai, K, Takahashi, K, Suwabe, A, Takada, K, Ikeda, H, Sato, S, and Yasui, S: The effect of cigarette smoke on bleomycin-induced pulmonary fibrosis in hamsters. Am Rev Respir Dis 138 : 1276-1281, 1988.

20. Ekimoto, H, Takahashi, K, Matsuda, A, and Umezawa, $\mathrm{H}$ : Animal models on BLM-induced pulmonary fibrosis: Comparison of the systemic (intraperitoneal) administration with the local (intratracheal) instillation. Jpn J Cancer Chemother 10 : 2550-2557, 1983. 